Research Article

\title{
Influence of clay modification process in polypyrrole-layered silicate nanocomposite
}

\author{
L. $\operatorname{Mrah}^{1}$ (D) R. Meghabar ${ }^{1}$
}

Received: 10 January 2020 / Accepted: 25 February 2020 / Published online: 16 March 2020

(c) Springer Nature Switzerland AG 2020

\begin{abstract}
This work focuses mainly on the preparation and characterization of polypyrrole/organically modified clay nanocomposites. Organoclay/polypyrrole nanocomposites were prepared by oxidative polymerization of pyrrole in aqueous medium using ferric chloride as the oxidant. Initially, cetyltrimethyl-ammonium bromide and tetrabutyl-ammonium hydrogen sulphate were used as organophilic to modify clay and form an organic clay. After that, polypyrrole/organically modified clay nanocomposites were synthesized by in situ polymerization process in which pyrrole was polymerized in the presence of different proportions of organic clay. The effects of the nature of the organic clays and the preparation method were studied in order to evaluate their structural, morphological and thermal properties. X-ray diffraction (SAXS), Fourier transform infrared spectroscopy, scanning electron microscopy, thermogravimetric analysis, transmission electron microscopy, were used to define the characteristics of the materials obtained. The obtained results confirm the intercalation of molecules of salt in the clay layers, and good interaction with the polymer. Thermogravimetric analysis showed better thermal stability of nanocomposites compared to pure polypyrrole. The conductivity behaviour of nanocomposites was also examined.
\end{abstract}

\section{Graphic abstract}

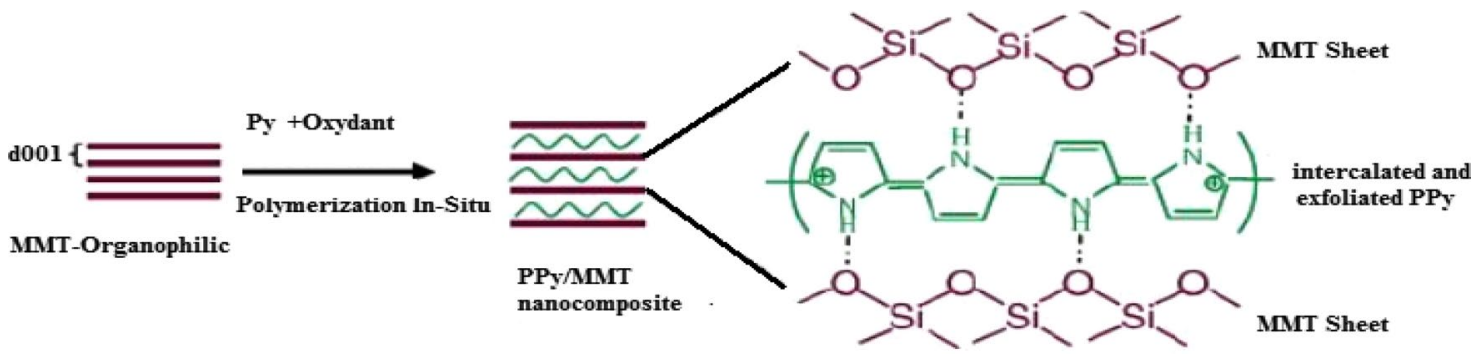

Keywords Pyrrole $\cdot$ Montmorillonite $\cdot$ Conductivity $\cdot$ Nanocomposite $\cdot$ Thermogravimetric analysis (TGA)

L. Mrah, Imrah@yahoo.fr | 'Laboratoire de Chimie des Polymères, Département de Chimie, FSEA, Université Oran1 Ahmed Ben Bella, BP $\mathrm{N}^{\circ} 1524$ El M'Naouar, 31000 Oran, Algeria. 


\section{Introduction}

In the last decade, a lot of attention has been devoted to the synthesis and application of nanocomposites with a clay-polymer matrix. Polyolefins, such as polyethylene and polypropylene, are the most commonly used polymers for clays containing nanocomposites [1-3]. Lamellar clays of the montmorillonite (MMT) type have been the subject of considerable interest for the manufacture of polymer-clay nanocomposites. These inorganic/organic nanocomposites have new and enhancing properties that individual inorganic and organic components do not possess [4-9]. Conjugated or conductive polymers have emerged as a highly promising class of materials for various applications. Their physical and chemical properties make them particularly attractive. The main classes of organic conductive polymers are polyacetylenes, polypyrroles, polythiophenes and polyanilines. They could have very interesting applications in the field of electrical and electronic components since they are very light [10], they can be used as organic semiconductors, electroluminescent materials, coatings for magnetic shielding, active energy storage materials, electrochemical systems [11] antistatic and anticorrosive coating materials, sensors and batteries [12]. These polymers are obtained by electrosynthesis, chemical or oxidative processes depending on the application. Polymerisation is a field of application that seeks an efficient way to produce polymers of a renewable nature, for example by using sustainable resources and developing solvent-free polymerisation processes [13]. The purpose of green chemistry is to develop chemical products and processes that reduce or eliminate the use and synthesis of hazardous substances. It is based on several principles. To meet industry standards while respecting the environment, acids have been replaced by another clay-based ecocatalyst called Maghnite. The latter is of the montmorillonite type and has been the subject of several studies [14-16]. The clay layer has a hydrophilic character and metamorphoses into organoclay (surfactant) to facilitate the wetting of the polymer molecule on the clay surface $[17,18]$. Miyata et al. [19, 20] studied the typical chemical synthesis of PPy using $\mathrm{FeCl}_{3}$ as oxidant/dopant in various solvents. They considered methanol to be the best solvent for optimal conductivity and morphology. The resulting polymer demonstrated a more harmonious fibrillar morphology and more tense films. Chen et al. [21] it was also possible to prove that the monomer/oxidant ratio established the electrical conductivity and morphology of the PPy thus obtained. Maximum conductivity has been established at a value of 2:1 monomer/oxidant ratio. In this work, we will highlight an ecocatalyst (clay) by modifying it by exchange with organoclay cations by using it in the synthesis of a conductive polymer based on pyrrole. Surfactants are known to have greater dispersive power at much lower concentrations and a singular capacity for self-organization, which will allow their distribution within the clay. The detailed thermal and morphological properties were studied to get a good overview of the main parameters that can be controlled to determine the structure of the nanocomposite and therefore the properties of the nanocomposite PPy/clay. We are going to optimize the pyrrole/clay mass ratios to obtain the best electrical conductivity as this improvement in properties opens great prospects for the use of these materials in the electronics industry. The objective of this work is to use a local montmorillonite type clay, called Maghnite, as an eco-catalyst in this polymerization by studying the effect of an organic clay prepared with different reports on the properties of PPy/Algeria clay nanocomposites.

\section{Materials and methods}

\subsection{Materials}

Pyrrole (Py) and cetyltrimethylammonium bromide, tetrabutyl ammonium hydrogen sulphate (TBAHS) and ferric chloride $\mathrm{FeCl}_{3}$ were supplied by Aldrich and used without further purification. Raw-Maghnite: Algerian montmorillonite clay that was used as a catalyst is supplied by a local company. The various chemical elements in the local maghnite were transformed into oxides and analysed by X-ray fluorescence (experiment carried out at the ENOF). These results make it possible to verify that the maghnite used is basically composed of montmorillonite, since the $\mathrm{SiO}_{2} / \mathrm{Al}_{2} \mathrm{O}_{3}$ ratio is equal to 3.77 and therefore belongs to the family of phyllosilicates.

\subsection{Preparation of maghnite- $\mathrm{Na}^{+}$}

Sodium ions are often chosen as compensating ions because they are more easily hydrated and promote the swelling and dispersion of montmorillonite in water. A mass of raw Maghnite (10 g) was placed in a volume of distilled water $(40 \mathrm{ml})$, this mixture was left in suspension under magnetic stirring and at temperature ambient for $2 \mathrm{~h}$. After $2 \mathrm{~h}$, a volume $(60 \mathrm{ml})$ of sodium chloride solution $(\mathrm{NaCl}, 0.2 \mathrm{M})$ was added to the previous mixture and stirred for $48 \mathrm{~h}$. After this time, the Maghnite-Na + was filtered and washed several times with distilled water in order to remove $\mathrm{Cl}$ - ions. After filtration, the Maghnite- $\mathrm{Na}^{+}$ was dried in the oven for $24 \mathrm{~h}$ at a temperature of $105^{\circ} \mathrm{C}$, 
afterwards it is finely ground and stored in a dry place [22, 23].

\subsection{Organic modification of clay}

Two types of organo-modified clays were prepared by cation exchange, using sodium maghnite and two surfactants: cetyltrimethyl-ammonium bromide (CTAB) and tetrabutyl-ammonium hydrogen sulphate (TBAHS) at different concentrations. A quantity of $10 \mathrm{ml}$ of $1 \mathrm{~N}$ hydrochloric acid was added to each of the two one-litre volumetric flasks and then the volume was made up with distilled water. The two solutions obtained were then poured into each vial equipped with a magnetic stirrer, and the acid solutions were placed at a temperature of $80^{\circ} \mathrm{C}$. When the temperature became stable, $10^{-2} \mathrm{~mol}$ of cetyltrimethylammonium bromide and tetrabutyl ammonium hydrogen sulfate (TBAHS) were introduced separately into each mixture. After $3 \mathrm{~h}$ of stirring at $80^{\circ} \mathrm{C}$, the amine was dissolved and ionized for both solutions. Then $5 \mathrm{~g}$ of sodium maghnite were added, after $3 \mathrm{~h}$ of cation exchange, the modified maghnite was recovered and rinsed six times in a row with distilled water at $80^{\circ} \mathrm{C}$ to remove the mineral cations. The effectiveness of this rinsing was verified by adding a few drops of silver nitrate to the residue. The physisorbed alkylammonium ions were removed with a mixture of water and ethanol, previously heated to $75^{\circ} \mathrm{C}$. The organophilic maghnite obtained was then dried at $120^{\circ} \mathrm{C}$

Table 1 Experimental condition for the preparation of MaghniteOrganophile

\begin{tabular}{lllll}
\hline Clay & Time (h) & Volume (l) & Type of clay & Concentration \\
\hline Maghnite-CTA $^{+}$ & 24 & 1 & CTAB & 1 CEC, 2 CEC \\
Maghnite-TBA $^{+}$ & 24 & 1 & TBAHS & 1 CEC \\
\hline
\end{tabular}

and ground. This method makes it possible to determine two organic clays called Maghnite-CTA ${ }^{+}$and Maghnite$\mathrm{TBA}^{+}$throughout this study $[24,25]$.

\subsection{Preparation of the nanocomposites}

$0.53 \mathrm{~g}$ ( $8 \mathrm{~mol}$ ) of pyrrole monomer (freshly distilled) was introduced into two separate vessels, a mass percentage of modified clays $(0.2,1,3.5$ and $10 \%)$ was added to each vessel which is kept under agitation for $30 \mathrm{~min}$ to allow the monomer to settle into the clay structure. Next, a $\mathrm{Fecl}_{3}$ polymerisation initiator $(0,1 \mathrm{M})$ of a $100 \mathrm{ml}$ volume solution was added to the mixture in each vessel with stirring at $400 \mathrm{rpm}$ for $24 \mathrm{~h}$ at room temperature (The operating conditions are shown in Table 1). Each nanocomposite obtained at the end of the reaction has been filtered and washed successively with distilled water, methanol and acetone several times until traces of oxidant disappear, eventually, it will be dried at $60^{\circ} \mathrm{C}$ [9] (Fig. 1).

\subsection{Characterization}

The infrared spectra were drawn on a Perkin Elmer IR TWO spectrophotometer equipped with an ATR, in the range $400-4000 \mathrm{~cm}^{-2}$. The $X$-ray diffraction analysis (XRD) was performed at room temperature in a Bruker D8 Advance X-ray diffractometer ( $40 \mathrm{kV}, 30 \mathrm{~mA})$. Thermogravimetric (TGA) and differential scanning calorimetric (DSC) analyses of clay samples were measured on Shimadzu TGA 51 equipment, using an air flow rate of $50 \mathrm{ml} / \mathrm{min}$ and a heating rate of $10.0^{\circ} \mathrm{C} / \mathrm{min}$. Transmission electron micrographs (TEM) were performed on a Hitachi 8100 . The electrical conductivity was measured using an Ohm meter (Advantest, Digital electrometer,
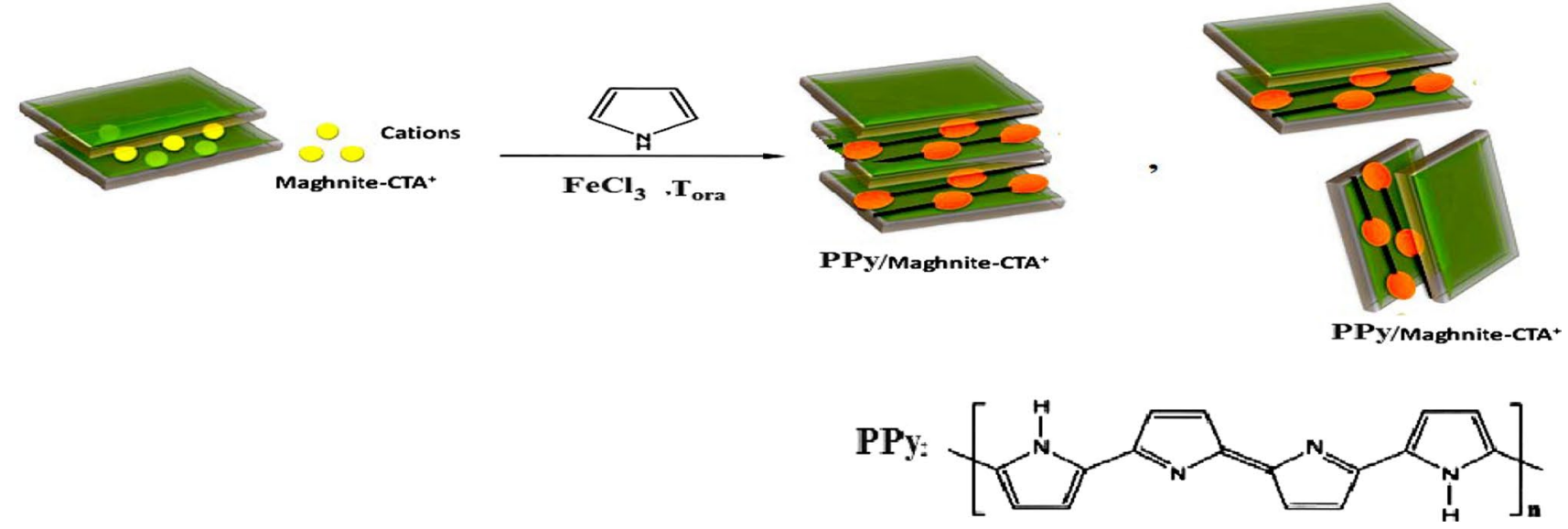

Fig. 1 Diagram of the incorporation of the PPy into the Maghnite-CTA 


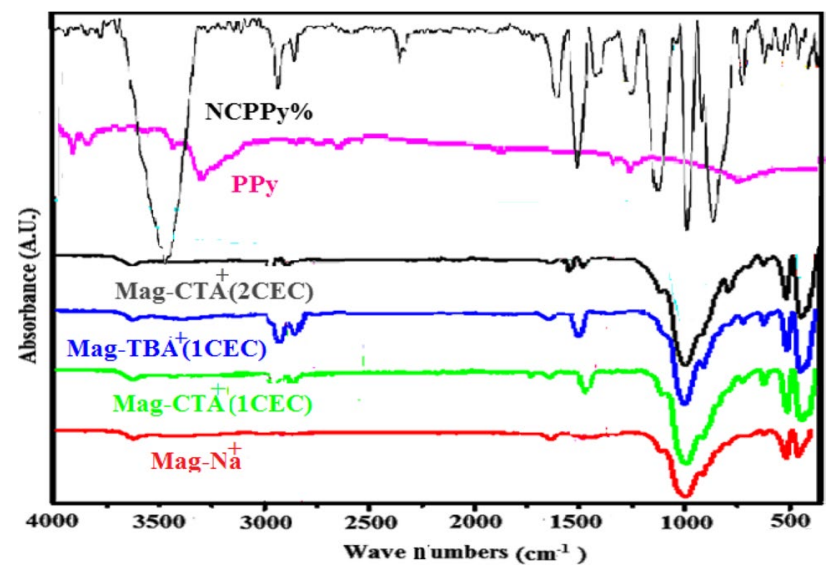

Fig. 2 FTIR spectra of, Mag-Na ${ }^{+}, \mathrm{Mag}^{-\mathrm{CTA}^{+}}$, Mag-TBA ${ }^{+}, \mathrm{PPy}$ and NCPPy

TR8652) (four-point method). The surface morphology of the prepared materials was observed by Scanning Electron Microscopy (SEM) "JEOL 7001F, FEG-SEM".

\section{Results and discussion}

\subsection{Infrared spectroscopy (IR)}

The infrared spectra of the PPyNC nanocomposites prepared by the different organoclays and organophilic Maghnite, Polypyrrole are shown in Fig. 2. These infrared spectra show that virgin PPy and nanocomposites have almost the same vibration bands that overlap with the vibration bands of organically modified clay. The absorption bands at $2925 \mathrm{~cm}^{-1}$ and $2854 \mathrm{~cm}^{-1}$ which are attributed to the valence vibrations of the $-\mathrm{CH}_{2}$ groups, as well as the band at $1544 \mathrm{~cm}^{-1}$ corresponds to the elongation of the $C=C$ bond in the pyrrole ring and the peak at $1271 \mathrm{~cm}^{-1}$ is induced by the $\mathrm{C}-\mathrm{N}$ stretch. A band is observed at $3450 \mathrm{~cm}^{-1}$ corresponds to the $\mathrm{N}-\mathrm{H}$ bond of PPy, the results obtained are comparable to those in the literature [26-31]. In addition, the bands between 784 and $675 \mathrm{~cm}^{-1}$ also indicate deformation vibrations of $\mathrm{N}-\mathrm{H}$ in the polymer and the absorption band at $835 \mathrm{~cm}^{-1}$, suggesting several interactions between PPy and the organically modified clay, there is an intense peak at $1057 \mathrm{~cm}^{-1}$ and two bands of 455 and $515 \mathrm{~cm}^{-1}$ related to the elongation and torsional vibrations of the $\mathrm{Si}-\mathrm{O}-\mathrm{Si}$ and $\mathrm{Si}-\mathrm{O}-\mathrm{Al}$ bonds, respectively furthermore the bands of 1440 and $1131 \mathrm{~cm}^{-1}$ confirm the protonation of the nitrogen atom in the polypyrrole. The wide bands at $1643 \mathrm{~cm}^{-1}$ and $3625 \mathrm{~cm}^{-1}$ are attributable to elongations of hydroxyl groups in water linked by hydrogen bonding to clay [32,33]. Also the characteristic peak of
PPy registered in PPy/Mag nanocomposite systems is a strong indication of PPy intercalation in nanocomposite systems.

\subsection{X-ray diffraction (XRD)}

Figure 3 shows the comparative diffractograms of Mag$\mathrm{Na}^{+}, \mathrm{Mag}^{-\mathrm{CTA}}{ }^{+}$(1CEC, 2CEC) and Mag-TBA ${ }^{+}$(2CEC). The XRD obtained are practically identical and indicate an incorporation of the alkyl chains of the surfactant in the Maghnite galleries. Indeed, for a concentration at $1 C E C$, the interfo-

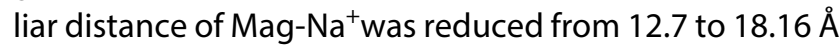
for Mag-CTA ${ }^{+}$(1CEC) corresponding to a "bilayer" organization. However, for a concentration of $2 \mathrm{CEC}$, a bimodal profile for Mag-CTA ${ }^{+}$(2CEC) is observed centred on two values $19.27 \AA$ and $33.53 \AA$. Concerning the second surfactant Fig. 3 also shows the Mag- $\mathrm{Na}^{+}$diffractograms exchanged with the prepared TBAHS $(1 C E C)$, there is a slight increase in the interfoliar distance indicating an insertion of the surfactant into the Maghnite galleries. This slight increase can be explained by the short alkyl chains (4 carbons) of the surfactant. Thus, $\mathrm{TBA}^{+}$ions adopt a monolayer conformation.

The series of nanocomposites generated by the in situ polymerization of Py is illustrated in Figs. 4, 5 and 6 . The pyrrole is represented by an important peak at $2 \theta=24.6^{\circ}$, the peak characterizes the amorphous polypyrrole [34]. These peaks were also detected in nanocomposites with the appearance of additional peaks characteristic of the Maghnite organophilic, confirming its good dispersion in the polymer matrix. All nanocomposites elaborated by Mag-CTA ${ }^{+}\left(1\right.$ CEC) showed a peak around $2 \Theta \approx 5.75^{\circ}$ corresponding respectively to the distances between the layers $d 001 \approx 16.65-18.9 A^{\circ}$. The distance between the layers of these nanocomposites decreased compared to the Mag-CTA ${ }^{+}(1 \mathrm{CEC})$, which had a d001 $\approx 18.1 \AA$ A. This result confirms the intercalation of PPy in the Mag-CTA +(1CEC). The preparation of nanocomposites by Mag$\mathrm{CTA}^{+}(2 \mathrm{CEC})$ showed the displacement of the basal peak

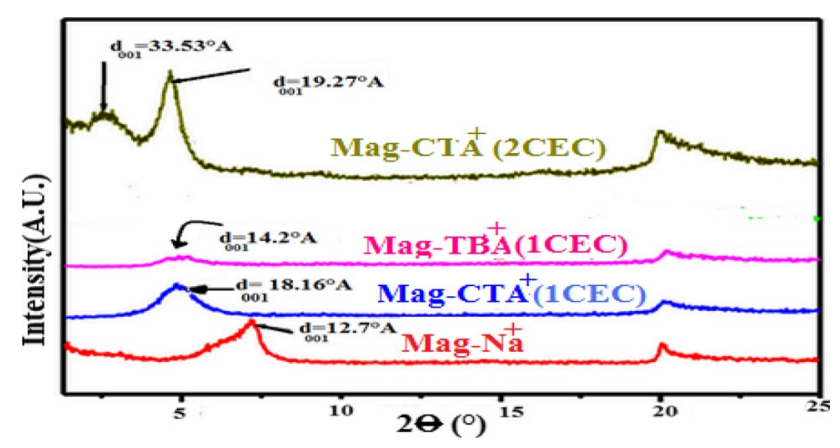

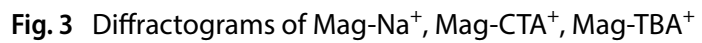




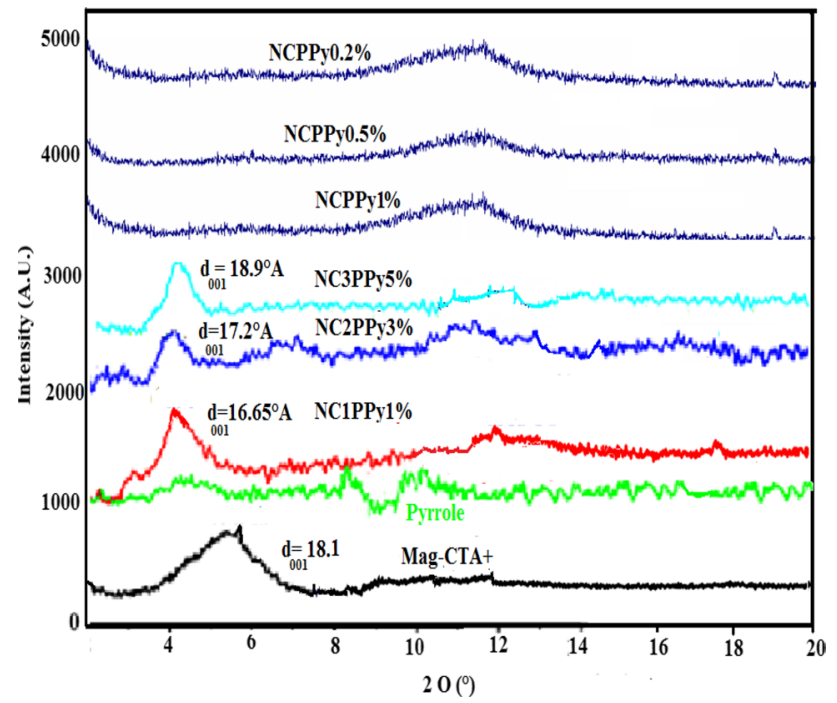

Fig. 4 Diffractograms of the different NCPPy nanocomposites prepared by Mag-CTA ${ }^{+}(1 \mathrm{CEC})$

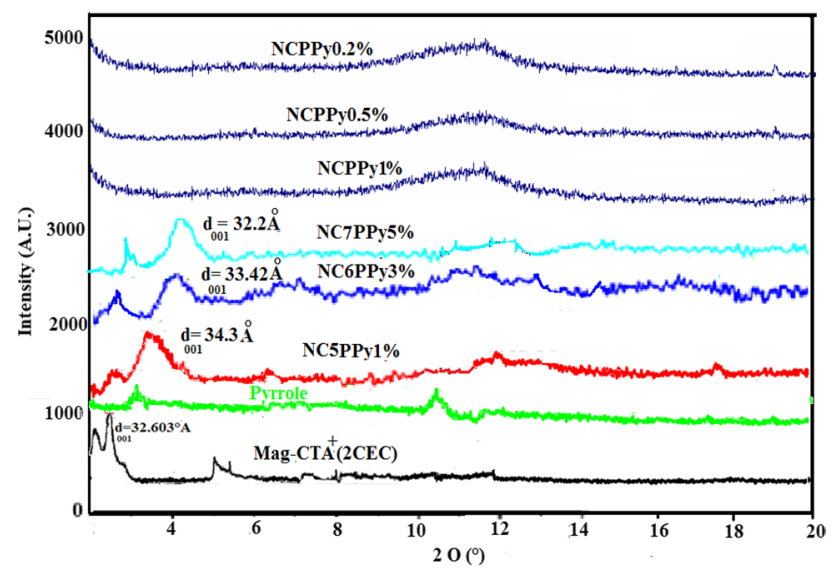

Fig. 5 Diffractograms of the different NCPPy nanocomposites prepared by the Mag- $\mathrm{CTA}^{+}(2 \mathrm{CEC})$

d001 at low angles between $2 \Theta \approx 2.6-2.5^{\circ}$, the distances between the layers being respectively from 34.3 to 33.4 Å thus confirming their intercalated shapes (Fig. 5). Except for nanocomposites prepared with 10\% Mag$\mathrm{CTA}^{+}(2 \mathrm{CEC})$, the polymerization of Py reveals a partially intercalated structure of low-yielding clay (Table 2), due to the closure of the clay galleries leading to tortuous diffusion pathways, these results are consistent with those obtained in the literature [35]. Similar results were obtained using Mag-TBA ${ }^{+}(1 \mathrm{CEC})$ as a reinforcement in the synthesis of nanocomposites showing intercalated structures (Fig. 6). On X-ray diffractograms relating to $0.5 .1 \%$ by weight of clay, the nanocomposites PPy/Mag$\mathrm{CTA}^{+}$(1CEC, 2CEC), PPy/Mag-TBA ${ }^{+}$(1CEC) (Figs. 4, 5 and 6)

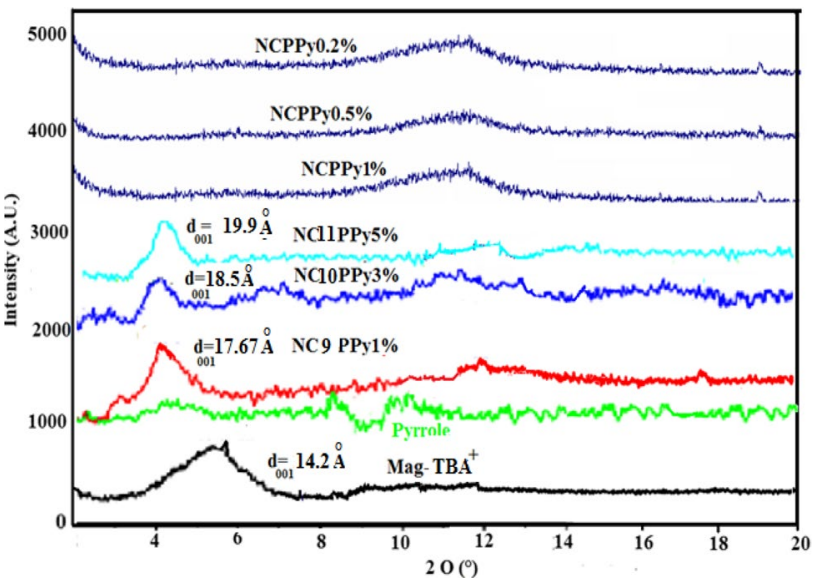

Fig. 6 Diffractograms of the different NCPPy nanocomposites prepared by Mag-TBA ${ }^{+}(\mathrm{CEC})$

Table 2 Experimental conditions for the preparation of nanocomposites by in situ polymerization

\begin{tabular}{lll}
\hline Sample name & Organic clay & Yields (\%) \\
\hline NC1PPy1 & Mag-CTA ${ }^{+}$(1CEC)1\% & 85.36 \\
NC2PPy3 & Mag-CTA $^{+}$(1CEC)3\% & 81.29 \\
NC3PPy5 & Mag-CTA $^{+}$(1CEC)5\% & 78.15 \\
NC4PPy10 & Mag-CTA $^{+}$(1CEC)10\% & 70.57 \\
NC5PPy1 & Mag-CTA $^{+}$(2CEC)1\% & 47.69 \\
NC6PPy3 & Mag-CTA $^{+}$(2CEC)3\% & 45.78 \\
NC7PPy5 & Mag-CTA $^{+}$(2CEC)5\% & 37.95 \\
NC8PPy10 & Mag-CTA $^{+}$(2CEC)10\% & 23.93 \\
NC9PPy1 & Mag-TBA $^{+}$(1CEC)1\% & 88.2 \\
NC10PPy3 & Mag-TBA $^{+}$(1CEC)3\% & 79.31 \\
NC11PPy5 & Mag-TBA $^{+}$(1CEC)5\% & 72.57 \\
NC12PPy10 & Mag-TBA $^{+}$(1CEC)10\% & 68.78 \\
\hline
\end{tabular}

show a significant peak corresponding to PPy, however, no clay peak appears, which makes it possible to conclude the presence of an exfoliation of montmorillonite in the polymer matrix.

\subsection{Transmission electron microscope (TEM)}

Transmission electron microscopy is the most widely used qualitative technique for characterizing polymer-clay nanocomposite dispersions and to confirm the results obtained by DRX analysis, the nanocomposites obtained are illustrated in Fig. 7. The nanocomposite obtained by Mag-CTA ${ }^{+}(1 \mathrm{CEC})$ showed an intercalated structure of the modified clay. The TEM image of the nanocomposite NCPPy/Mag-CTA ${ }^{+}((1 \mathrm{CEC})$ With 3 wt. $\%$ and $10 \%$ shows an intercalated morphology (Fig. 7a NC2PPy, b NC4PPy10/ Mag-CTA $\left.{ }^{+}(1 C E C)\right)$, which corresponds to the results found 

composites a NC2PPy/Mag$\mathrm{CTA}^{+}(1 \mathrm{CEC}), \mathbf{b} \mathrm{NC} 4 \mathrm{PPy} 10 /$ Mag-CTA ${ }^{+}(1 \mathrm{CEC})$, c NC6PPy3/ Mag-CTA ${ }^{+}(2 \mathrm{CEC}), \mathbf{d}$ NC8PPy10/Mag-CTA ${ }^{+}(2 \mathrm{CEC})$, e NC10PPy3/Mag-TBA ${ }^{+}(1 \mathrm{CEC}), \mathbf{f}$ NC12PPy10/Mag-TBA ${ }^{+}$(1CEC)
Fig. 7 MET images of nano-
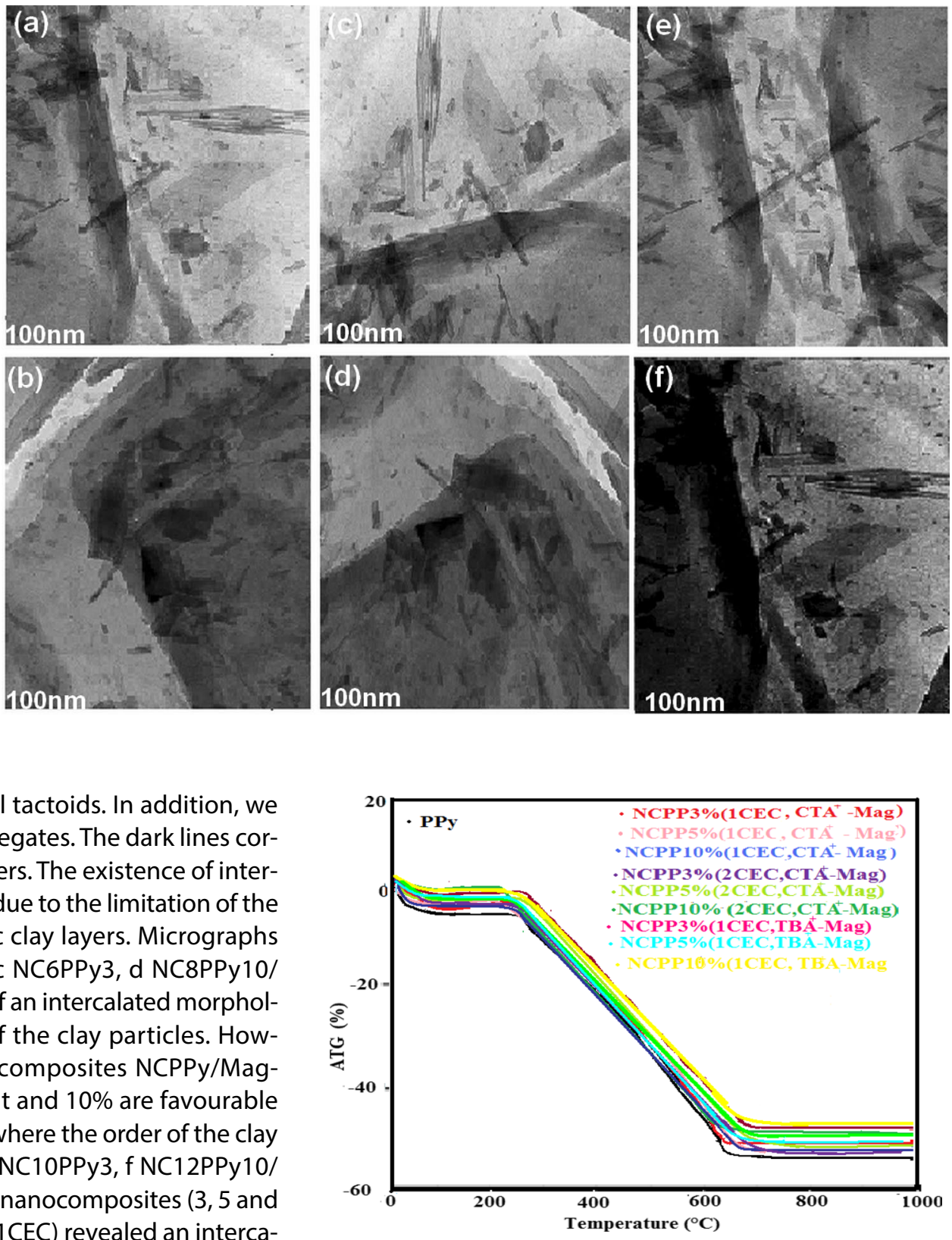

by DRX with a presence of small tactoids. In addition, we note the presence of some aggregates. The dark lines correspond to the silicate monolayers. The existence of intercalated clay regions is probably due to the limitation of the diffusion of PPy in organophilic clay layers. Micrographs of the nanocomposites (Fig. 7c NC6PPy3, d NC8PPy10/ Mag-CTA ${ }^{+}(2 \mathrm{CEC})$ ) are in favour of an intercalated morphology that preserves the order of the clay particles. However, micrographs of the nanocomposites NCPPy/MagTBA $+(1 C E C)$, With $3 \%$ by weight and $10 \%$ are favourable to an intercalated morphology where the order of the clay particles is maintained (Fig. 7e NC10PPy3, $\mathrm{f} \mathrm{NC12PPy} 10$ / Mag-TBA + (1CEC)). The series of nanocomposites ( 3,5 and 10\%) developed by Mag-TBA + (1CEC) revealed an intercalated structure, these results are in agreement with those of DRX. On the other hand The TEM image of the PPy nanocomposites with 0.5 and $1 \%$ by weight of the modified clay shows an exfoliated morphology, a degree of disorder in the morphology of the clay. The clay platelets are separated from each other which is in favour of an exfoliated structure.

\subsection{Thermal stability (TGA)}

The TGA curves for PPy and these nanocomposites are shown in Fig. 8. According to the TGA curves, PPy nanocomposites show several levels of degradation, the first being between 50 and $150^{\circ} \mathrm{C}$, which corresponds to the departure or loss of the bound and cross-linked
Fig. 8 ATG analyses of PPy, NCPPy/Mag-CTA ${ }^{+}$(1CEC, 2CEC) and NCPPy/Mag-TBA ${ }^{+}-(1 \mathrm{CEC})$

water molecules in the intercalated space. In this temperature range, approximately $\approx 05.06 \%$ mass loss, which confirms the hydrophobic character of PPy and organically modified clays. Decomposition of doping anions to PPy begins at $200{ }^{\circ} \mathrm{C}$ followed by a large mass loss of $260-630^{\circ} \mathrm{C}$ due to the significant thermal degradation of the PPy chains which corresponds to a $50 \%$ decrease. For pure PPy, polymer degradation and decomposition begins at $270{ }^{\circ} \mathrm{C}$, and the polymer appears to decompose entirely at $630^{\circ} \mathrm{C}$, while the thermal degradation of NCPPy composites all occurs at close to $262^{\circ} \mathrm{C}$, an

\section{SN Applied Sciences}


Table 3 Evolution of conductivity of PPy Nanocomposites as a function of the quantity of $\mathrm{TBA}^{+}$-Mag and $\mathrm{CTA}^{+}$-Mag

\begin{tabular}{lll}
\hline Load rate (\%) & $\begin{array}{l}\text { Conductivity of PPy/ } \\
\text { Mag-CTA }{ }^{+}(2 \mathrm{CEC}) \text { nano- } \\
\text { composites }\end{array}$ & $\begin{array}{l}\text { Conductivity of PPy/Mag- } \\
\text { TBA }^{+}(1 \mathrm{CEC}) \text { nanocom- } \\
\text { posites }\end{array}$ \\
\hline 0 & 1.41 & 0.61 \\
0.4 & 1.01 & 0.30 \\
0.6 & 0.87 & 0.22 \\
0.8 & 0.71 & 0.17 \\
1 & 0.64 & 0.12 \\
3 & 0.053 & 0.073 \\
5 & 0.015 & 0.013 \\
10 & 0.0082 & 0.002 \\
\hline
\end{tabular}

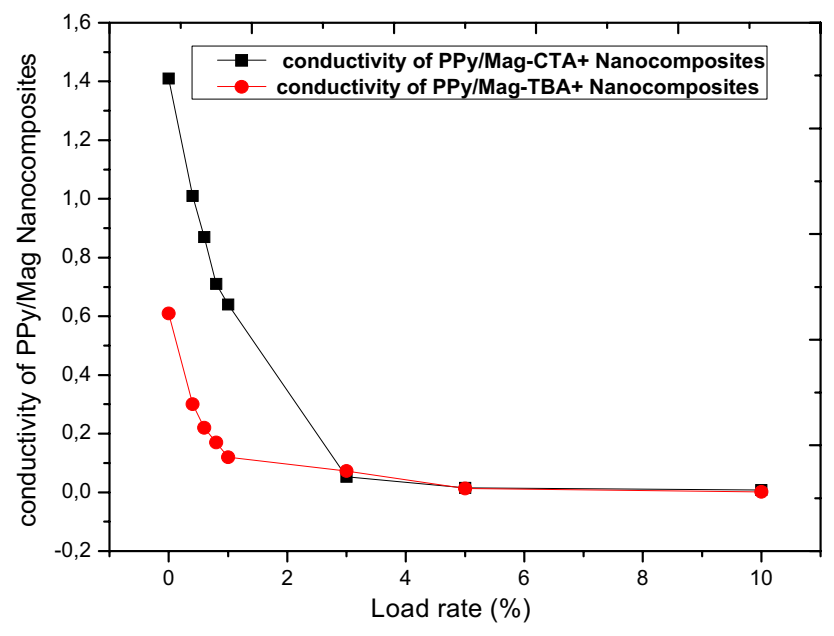

Fig. 9 Evolution of conductivity of nanocomposites as a function of the quantity of $\mathrm{TBA}^{+}-$Mag and $\mathrm{CTA}^{+}$-Mag increase of $12{ }^{\circ} \mathrm{C}$ over virgin PPy. These results clearly show that the thermal stability of the nanocomposites obtained is related to the content and nature of the clay, the state of existence of the clay in the polymer matrix (intercalation or exfoliation), so it can be concluded that the experimental results obtained are in accordance with the literature $[36,37]$.

\subsection{Electrical conductivity}

Table 3 shows the following results, the highest electrical conductivity being that of PPy/Mag-CTA + (2 CEC) nanocomposites of the order of $1.41 \mathrm{~S} / \mathrm{cm}$, while that of PPy/Mag TBA + (1 CEC) nanocomposites is of the order of $0.61 \mathrm{~S} / \mathrm{cm}$. We notice from the table that the electrical conductivity decreases with increasing charge rate in the two nanocomposites PPy/Mag-CTA + and PPy/Mag-TBA + . The results show that good electrical conductivity is obtained using a small amount of organophilic Maghnite for $1 \%$ by weight and continues to decrease to $10 \%$ by weight (Fig. 9). The decrease in conductivity to $10 \%$ of the amount of organophilic Maghnite can be explained by the fact that Maghnite acts as an insulator once its amount is increased. Maghnite acts as an oxidizing support, bearing in mind that the chemical synthesis of conductive polymers in general requires the presence of an oxidizing agent. Montmorillonite hinders the relocation of electrons along polymer chains and limits inter-chain movement.

\subsection{Scanning electron microscope}

Figures 10 and 11 illustrate the SEM images of the different PPy/clay nanocomposites obtained, the images
Fig. 10 SEM images of nanocomposites NCPP3\%/Mag-CTA + (1CEC) and NCPP3\%/Mag$T B A^{+}$(1CEC)
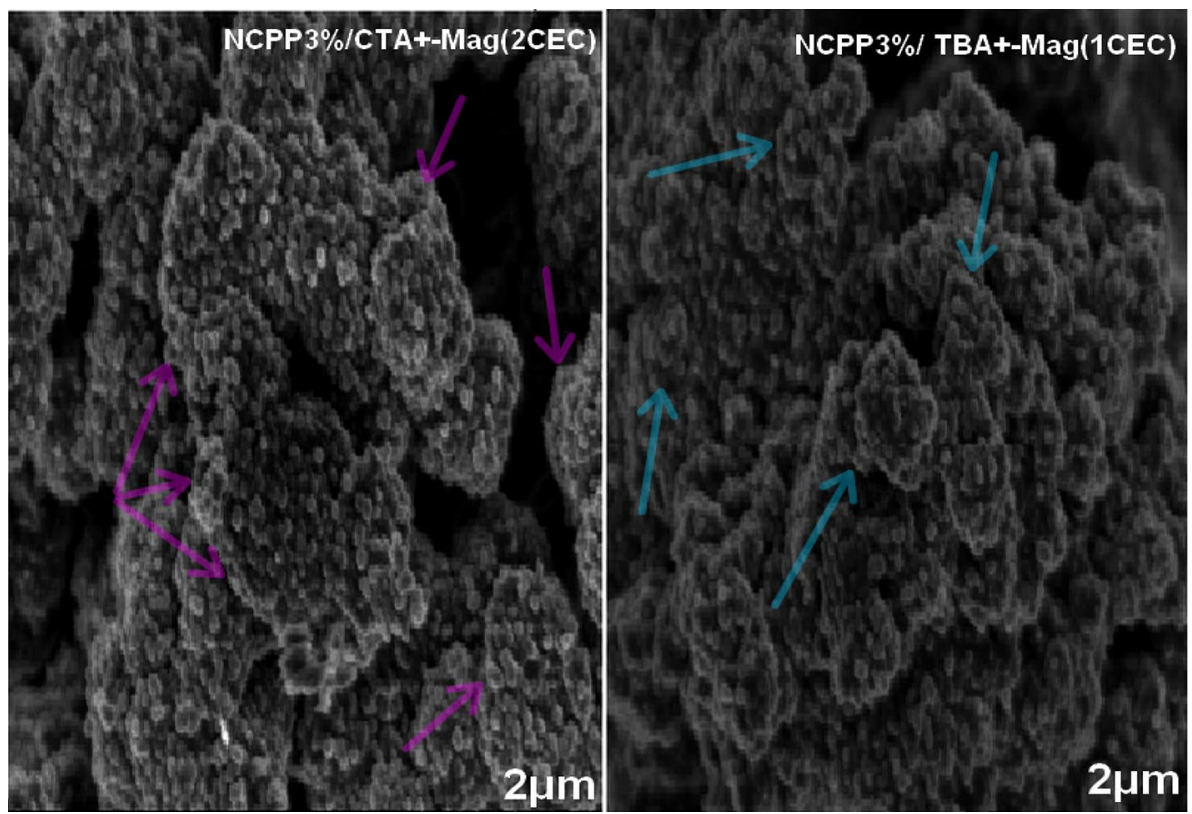
Fig. 11 SEM images of nanocomposites NCPP10\%/Mag$\mathrm{CTA}^{+}(2 \mathrm{CEC})$ and NCPP10\% Mag-TBA ${ }^{+}(1 \mathrm{CEC})$

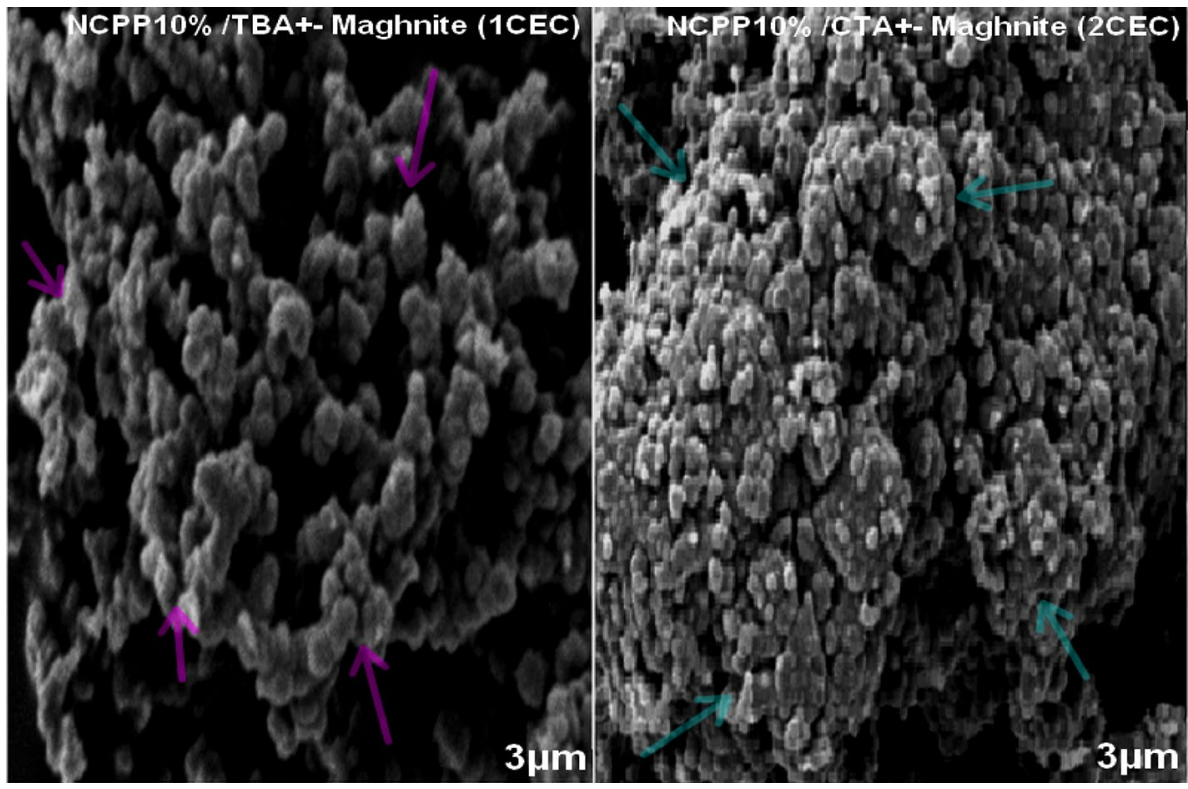

show during polymerization, the clay particles were not visible on the surface of the NCPP nanocomposites. The micrograph shown in Figs. 10 and 11 illustrates a more ordered and denser structure. Smaller aggregates with a high density of the granules are better observed for loading rates of $1 \%$, whereas these aggregates are larger with a lower density per unit area for loading rates of 3.5\% (these aggregates are observed by arrows in Figs. 10 and 11). This shows that increasing loading rates in nanocomposites increase the compactness of the samples which become denser. The clay particles have been coated by the polymer (Fig. 10), and can be enhanced by an attractive interaction between the PPy and the surface clay, the polymer is probably bound to the surface by a hydrogen bond between the amine groups of the polymer and the surface oxygen of the clay. The Poly(pyrrole) is in the form of non-uniformly distributed agglomerates, in the case of $10 \%$ clay, these organically modified clay particles are more dense (Fig. 11). There are interactions between amines and surface silicates in organophilic Maghnite [38]. The microstructure of a thin layer of polypyrrole is shown in Fig. 11. The film has a uniform granular morphology and the average grain size is approximately $0.5 \mu \mathrm{m}$.

\subsection{Thermal analysis (DSC)}

We observe on the thermogram of the PPy- Mag \% nanocomposites the presence of a first endothermic peak located between 105 and $121{ }^{\circ} \mathrm{C}$ which indicates the departure of water. A second endothermic peak is located between 250 and $290{ }^{\circ} \mathrm{C}$ which is related to the decomposition of the surfactant (CTAB, TBAHS). A third peak is located around $425^{\circ} \mathrm{C}$ and $505^{\circ} \mathrm{C}$ which is linked to the cross-linking of the polymer chains which is delayed compared to that of polypyrrole, and finally an endothermic peak is located around $507^{\circ} \mathrm{C}$ and $549^{\circ} \mathrm{C}$ which indicates the decomposition of the nanocomposite. The DSC analysis was performed in order to study the influence of the loading rate on the glass transition temperature of the matrix. According to Fig. 12, the Tg of the PPy/MMT \% nanocomposites is higher than that of polypyrrole which is $75.46^{\circ} \mathrm{C}$, this slight increase is due to the introduction of clay into the matrix which makes it more rigid.

\section{Conclusion}

This work deals with the implementation of PPy/Maghnite-Organophile nanocomposites and the characterization by different analyses (IR, TGA and DRX, SEM, TEM, DSC) which allowed to quantify the quantity of surfactants incorporated in the clay and the spacing between the clay layers. The existance of PPy within the interlayer of clay has been verified by XRD, FTIR, and SEM, TEM studies. Electrical conductivity measurements show a decrease in conductivity with increasing charge rates. The results of thermogravimetric analysis show a significant improvement in the thermal stability of the different nanocomposites developed compared to virgin PPy. Currently, we are investigating the possibility of coating these nanocomposites on coated surfaces for applications in electronic device covers. 
Fig. 12 Thermal analysis (DSC) of PPy-Maghnite nanocomposites

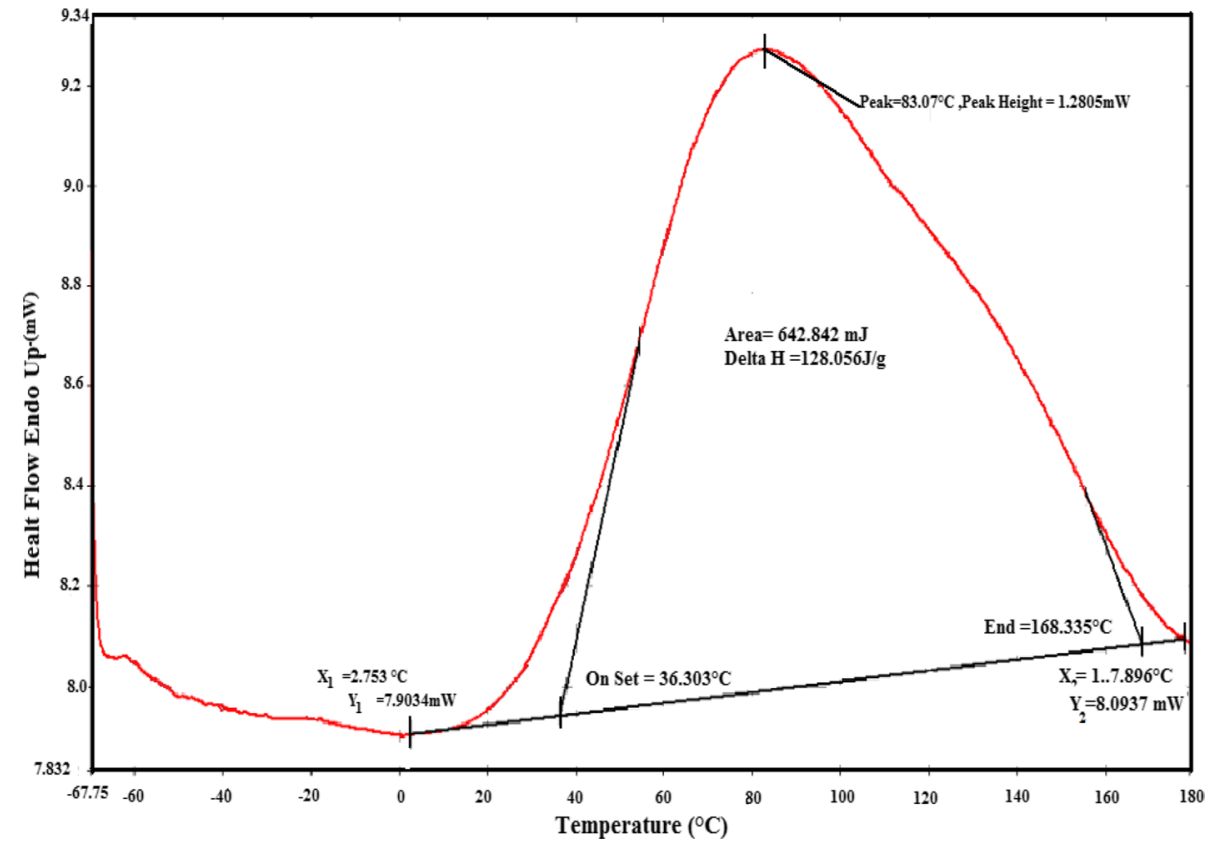

\section{Compliance with ethical standards}

Conflict of interest The authors declare that they have no conflict of interest.

\section{References}

1. Izak P, Ogłaza L, Mozgawa W, Mastalska-Popławska J, Stempkowska A (2018) Influence of the type of aqueous sodium silicate on the stabilization and rheology of kaolin clay suspensions. Spectrochim Acta Part A Mol Biomol Spectrosc 196:155159. https://doi.org/10.1016/j.saa.2018.02.022

2. Stempkowska A, Mastalska-Popławska J, Izak P, Ogłaza L, Turkowska M (2017) Stabilization of kaolin clay slurry with sodium silicate of different silicate moduli. Appl Clay Sci 146:147-151. https://doi.org/10.1016/j.clay.2017.05.046

3. Garcia-Lopez D, Picazo O, Merino JC, Pastor JM (2003) Polypropylene-clay nanocomposites: effect of compatibilizing agents on clay dispersion. Eur Polym J 39:945-950. https://doi. org/10.1016/S0014-3057(02)00333-6

4. Lepoittevin B, Pantoustier N, Devalckenaere $M$, Alexandre $M$, Kubies D, Calberg $C$, Jérôme R, Dubois $P$ (2002) Poly $(\varepsilon-$ caprolactone)/clay nanocomposites by in situ intercalative polymerization catalyzed by dibutyltin dimethoxide. Macromolecules 35:8385-8390. https://doi.org/10.1021/ma020300w

5. Hári J, Horváth F, Móczó J, Renner K, Pukánszky B (2017) Competitive interaction structure and properties in polymer/layered silicatenanocomposites. Exp Polym Lett 11:479-492. https://doi. org/10.3144/expresspolymlett.2017.45

6. Longo S, Mauro M, Daniel C, Galimberti M, Guerra G (2013) Clay exfoliation and polymer/clay aerogels by supercritical carbon dioxide. Front Chem 1:28. https://doi.org/10.3389/fchem .2013 .00028

7. Amurin LG (2016) Morphological evolution of block copolymer nanocomposites submitted to extensional flows. J Rheol 60:175. https://doi.org/10.1122/1.4938278
8. Maiti P, Nam PH, Okamoto M, Hasegawa N, Usuki A (2002) Influence of crystallization on intercalation, morphology, and mechanical properties of polypropylene/clay nanocomposites. Macromolecules 35:2042-2049. https://doi.org/10.1021/ma010 $852 z$

9. Hosseini MG, Raghibi-Boroujeni M, Ahadzadeh I, Najjar R, Seyed Dorraji MS (2009) Effect of polypyrrole-montmorillonite nanocomposites powder addition on corrosion performance of epoxy coatings on Al 5000. Prog Org Coat 66:321-327. https:// doi.org/10.1016/j.porgcoat.2009.08.010

10. Huber T, Saville P, Makeiff D (2005) Fabrication of organic radar absorbing materials. DRDC Atlantic TR, p 124

11. Trivedi DC (1997) Handbook of organic conductive molecules and polymers, volume 2. In: Nalwa HS (ed) Conductive polymers: synthesis and electrical properties. Willey, New York

12. Can M, Özaslan H, Pekmez NO, Yildiz A (2003) Chemical synthesis of thiophene-pyrrole copolymer. Acta Chim Slov 50:741-750

13. Aurore $R$ (2011) Industrial biological chemistry unit University of Liège-Gembloux Agro-Bio Tech. Green chemistry. General principles and illustration for the valorisation of agroressources. Biomass \& Green Technologies Unit. http://progcours.ulg.ac.be/ cocoon/en/cours/CHIM0683-2.html

14. Embarek N, Sahli N, Belbachir M (2019) Preparation and characterization of poly(3-glycidoxypropyltrimethoxysilane) nanocomposite using organophilic montmorillonite clay (Magcetyltrimethylammonium). J Compos Mater 53:28-30. https:// doi.org/10.1177/0021998319857112

15. Rahmouni A, Belbachir M, Ayat M (2018) Structural investigation: anionic polymerization of acrylamide under microwave irradiation using maghnite- $\mathrm{Na}^{+}$clay (Algerien MMT) as initiator. Bull Chem React Eng Catal 13:262-274. https://doi.org/10.9767/ bcrec.13.2.1308

16. Bennabi S, Belbachir M (2017) Synthesis and characterization of a new organometallic hybrid material LCP-1 based on MOF (Metal-Organic Framework) and Maghnite- $\mathrm{H}+$, a proton-exchanged montmorillonite clay, as a catalyst support. J Inorg Organomet Polym Mater 27:1787-1799. https://doi. org/10.1007/s10904-017-0643-4 
17. Lu C, Mai YW (2005) Influence of aspect ratio on barrier properties of polymer-clay nanocomposite. Phys Rev Lett 95(8):8830388306. https://doi.org/10.1103/PhysRevLett.95.088303

18. Dennis HR, Hunter DL, Chang D, Kim S, White JL, Cho JW, Paul DR (2001) Effect of melt processing conditions on the extent of exfoliation in organoclay-based nanocomposite. Polymer 42:9513-9522. https://doi.org/10.1016/S0032-3861(01)00473-6

19. Waghuley SA, Yenorkar SM, Yawale SS, Yawale SP (2008) Application of chemically synthesized conducting polymer-polypyrrole as a carbon dioxide gas sensor. Sens Actuators, B 128(2):366373. https://doi.org/10.1016/j.snb.2007.06.023

20. Rajasudha G, Rajeswari D, Lavanya B, Saraswathi R, Annapoorni S, Mehra NC (2005) Colloidal dispersions of polyindole. Colloid Polym Sci 283:575-582. https://doi.org/10.1007/s0039 6-004-1189-x

21. Chen X, Devaux J, Issi JP, Billaud D (1995) Chemically oxidized polypyrrole: Influence of the experimental conditions on its electrical conductivity and morphology. Polym Eng Sci 35:642647. https://doi.org/10.1002/pen.760350803

22. Rahmouni A, Harrane A, Belbachir M (2013) Mechanochemical synthesis and characterization of donductive polyaniline catalyzed by maghnite- $\mathrm{H}^{+}$(Algerian Montmorillonite). Int J Adv Chem 1:5-12

23. Mrah L, Meghabar R, Belbachir M (2015) In situ polymerization of styrene to produce poly styrene/montmorillonite nanocomposites. Chem React Catal Eng Bull 10:249-255. https://doi. org/10.9767/bcrec.10.3.8708.249-255

24. Boufatit MM, Ait-Amar H, Mc Whinnie WR (2008) Development of an algerian material montmorillonite clay-Intercalation with selective long chain alkylammonium cations (Octadecytrimethylammonium, Cetylpyridium and Tetrabutylammonium) and with tellerium complexes Development of an algerian material montmorillonite. Desalination 223:366-374. https://doi. org/10.1016/j.desal.2007.01.204

25. Le Pluart L (2002) Nanocomposites, epoxyde, amine, montmorillonite: role of interactions on the formation, morphology at different levels of scale and mechanical properties of the networks. Ph.D., National Institute of Applied Sciences, Lyon

26. Peighambardoust SJ, Pourabbas Behzad (2007) Synthesis and characterization of conductive polypyrrole/montmorillonite nanocomposites via one-pot emulsion polymerization. Macromol Symp 247:99-109. https://doi.org/10.1002/masy.20075 0112

27. Xing S, Zhao G (2007) Morphology, structure, and conductivity of polypyrrole prepared in the presence of mixed surfactants in aqueous solutions. J Appl Polym Sci 104:1987-1996. https://doi. org/10.1002/app.25912

28. Kudoh Y, Akami K, Matsuya Y (1998) Properties of chemically prepared polypyrrole with an aqueous solution containing
Fe2(SO4)3, a sulfonic surfactant and a phenol derivative. Synth Met 95:191-196. https://doi.org/10.1016/S0379-6779(98)00054 $-X$

29. Kasisomayajula SV, Qi X, Vetter C, Croes K, Pavlacky D, Gelling VJ (2010) A structural and morphological comparative study between chemically synthesized and photopolymerized poly(pyrrole). J Coat Technol Res 7:145-158. https://doi. org/10.1007/s11998-009-9186-0

30. Carrasco PM, Grande HJ, Cortazar M, Alberdi JM, Areizaga J, Pomposo JA (2006) Structure-conductivity relationships in chemical polypyrroles of low, medium and high conductivity. Synth Met 156:420-425. https://doi.org/10.1016/j.synthmet.2006.01.005

31. Saraç AC, Ustamehmetoğlu B, Mustafaev MI, Erbil C, Uzelli $\mathrm{G}$ (1995) Oxidative polymerization of pyrrole in polymer matrix. J Polym Sci A Polym Chem 33:1581-1587. https://doi. org/10.1002/pola.1995.080331004

32. Huang ZM, Zhang Y-Z, Kotaki M, Ramakrishna S (2003) A review on polymer nanofibers by electrospinning and their applications in nanocomposites. Compos Sci Technol. 63:2223-2253. https://doi.org/10.1016/S0266-3538(03)00178-7

33. Katsumi Y, Kimur Y, Syoichi S, Junji S, Jun C, Shigeharu U (2006) Multiphoton-sensitized polymerization of pyrrole. Chem Lett 35:908-909. https://doi.org/10.1246/cl.2006.908

34. Chougule MA (2011) Synthesis and characterization of polypyrrole (PPy) thin films. Soft Nanosci Lett 01:6-10. https://doi. org/10.4236/snl.2011.11002

35. Salmi-Mani H, Ait-Touchente Z, Lamouri A, Carbonnier B, Caron JF, Benzarti K, Chehimi MM (2016) Diazonium salt-based photoiniferter as a new efficient pathway to clay-polymer nanocomposites. RSC Adv 6:88126-88134. https://doi.org/10.1039/ C6RA14713E

36. Zenasni MA, Meroufel B, Benfarhi S, Chehimi M, Molina S, George B, Ragoubi M, Merlin A (2013) Synthesis and characterization of polypyrrole/maghnite nanocomposites by in situ intercalative polymerization. Int J Chem 2(3):68

37. Omastova M, Trchova M, Kovarova J, Stejskal J (2003) Synthesis and structural study of polypyrroles prepared in the presence of surfactants. Synth Mater 138:447-455. https://doi.org/10.1016/ S0379-6779(02)00498-8

38. Pourabbas B, Pilati F (2010) Polypyrrole grafting onto the surface of pyrrole-modified silica nanoparticles prepared by one-step synthesis. Synth Met 160:1442-1448. https://doi.org/10.1016/j. synthmet.2010.05.002

Publisher's Note Springer Nature remains neutral with regard to jurisdictional claims in published maps and institutional affiliations. 